Acta vet. scand. $1981,22,417-427$.

From the Department of Animal Hygiene, College of Veterinary Medicine, Helsinki, Finland.

\title{
THE EFFECT OF GRAIN PRESERVATIVES ON THE GROWTH OF THE FUNGUS FUSARIUM GRAMINEARUM AND ON THE QUANTITY OF ZEARALENONE
}

By

\author{
K. Kallela and I. Saastamoinen
}

KALLELA, K. and I. SAASTAMOINEN: The effect of grain preservatives on the growth of the fungus Fusarium graminearum and on the quantity of zearalenone. Acta vet. scand. 1981, 22, 417-427. In the present study, the effects of preservatives, "Luprosilß" (propionic acid) and "Gasol" (contains organic acids and some additional compounds) on the growth of mycelium and the toxin content of stored grain (oats) infected by Fusarium and containing zearalenone have been examined.

The toxin quantity was determined before adding the preservatives quantitatively (by liquid chromatography) from the ether extracts of oats cultures and semiquantitatively (by bioassay) from the solid residues of the extracted grain cultures. The total amount of toxin in the contaminated grain was proved to be $2.5 \mathrm{mg}$ per $\mathrm{g}$ of dry matter.

Preservatives were added to the grain which contained $37 \%$ of dry matter: "Luprosil@" $0.08 \mathrm{ml}$ and "Gasol" $0.12 \mathrm{ml} / \mathrm{g}$ dry matter applying average or slightly high recommended doses.

The two preservatives completely prevented the growth of a visible mycelium. Propionic acid ("Luprosilß") had no influence on the toxin content of oats. "Gasol" decreased the percentage of the total toxin about $60 \%$ in 3 days, $85 \%$ in 14 days and $90 \%$ in 28 days.

Further investigations into this subject are now proceeding.

fresh preservation; Fusarium graminearum; zearalenone (F-2).

Some of the Fusarium fungi species synthetisize the toxins zearalenone and T-2 toxin under favourable conditions. The former toxin has been detected to cause disturbances in swine, and occasionally in cows (Roine et al. 1971). These disturbances found in swine have been manifested as the so called vulvo- 
vaginitis syndrome, and has disturbing influences on fertility in cows referred to as estrogenism.

The toxin is most commonly formed in grain when storage conditions are unsatisfactory. Favourable conditions for the production of the toxin are still incompletely known, but it appears that a combination of the right strain of fungus, a moisture content high enough to permit vigorous growth of the fungus, a period of relatively high or at least moderate temperature followed by a period of low temperature is necessary for the production of large quantities of the toxin (Christensen 1979).

Fusarium graminearum toxin, zearalenone is highly resistant to external conditions. It was, e.g., not destroyed at $80-120^{\circ} \mathrm{C}$ in a neutral medium (Lasztity et al. 1977). It has also been stated that at present the only effective control of zearalenone is avoidance (Christensen 1979).

Circumstances prevailing in Finland are favourable for the growth of Fusarium fungi species. In grain this mold is very common. More than $40 \%$, e.g., of spring cereal seed samples were infected by the species $F$. avenaceum, F. culmorum, F. poae or F. tricinctum and more than $10 \%$ by F. graminearum in 1972 (Uoti \& Ylimäki 1974). Manifested disturbances found in swine are relatively often caused by the Fusarium toxin.

Difficulties in drying grain have brought on the fact that the so called "fresh preservation" has become common practice in conserving feed grain. When the fresh preservation method is used the humid grain, unmilled or milled, is treated with a preservative solution. In the former case (whole grain preservation) the preservative now practically exclusively used is propionic acid, in the latter case the well-known conserving agents of silage containing mineral acids, organic acids and formalin are common. New preservatives have recently been developed for use, too.

The effect of the two preservatives, "Luprosil@" and "Gasol" on the growth of the mold Fusarium graminearum and on the amount of zearalenone formed in grain will be reported below.

"Luprosil@" is a propionic acid preparation of BASF, and "Gasol" is one of the Farmline Grain Preservatives produced by Farmos-Yhtymä Oy. "Gasol" contains organic acids and some additional compounds. 


\section{MATERIALS AND METHODS}

\section{Cultivation methods}

The cultivation of the mold Fusarium graminearum was performed on oats. The oats substrate which was autoclaved in Roux bottles and saturated with water was inoculated with a strain of Fusarium graminearum which in the field had caused the vulvovaginitis syndrome in swine. The inoculated grain was incubated for 2 weeks at a temperature of $+20-+24^{\circ} \mathrm{C}$, and after this incubation period the temperature was lowered to $+5^{\circ} \mathrm{C}$ for 2 days. When zearalenone could be detected (by liquid chromatography), the contaminated grain was finely milled, portioned out into 18 Petri dishes (25 g each) and spread as an even layer on the bottom. Six Petri dishes were treated with "Luprosil@", the other 6 with "Gasol", and the last 6 dishes were left untreated. The dosage of preservatives depends essentially on the moisture content of the grain to be preserved and varies in use from 5-30 l per $1000 \mathrm{~kg}$ of fresh grain. The moisture content of the milled grain was $63 \%$. Applying average or slightly higher doses than recommended "Luprosilß" was used in $0.08 \mathrm{ml} / \mathrm{g}$ dry matter and "Gasol" in $0.12 \mathrm{ml} / \mathrm{g}$ dry matter. The preservative solutions were distributed as evenly as possible on the grain substrate. In order to make the experimental conditions resemble the conditions of the internal parts of the stored grain mass concerning the supply of oxygen, the Petri dishes were wrapped hermetically with sheets of parafilm. These mold cultures were stored at room temperature. The grain was analysed immediately after milling and the Petri dish cultures after 3,14 and 28 days of storage. All samples were carried out in duplicate.

\section{Examination of the growth of mycelium}

The mold cultures in the Petri dishes were examined daily, and the quantity of the mycelium formed on the grain substrate was visually estimated.

\section{Determination of zearalenone}

Liquid-chromatographic method. The zearalenone content of the grain samples was determined by the liquid-chromatographic method which had been developed in the Department and described previously (Kallela \& Saasta- 


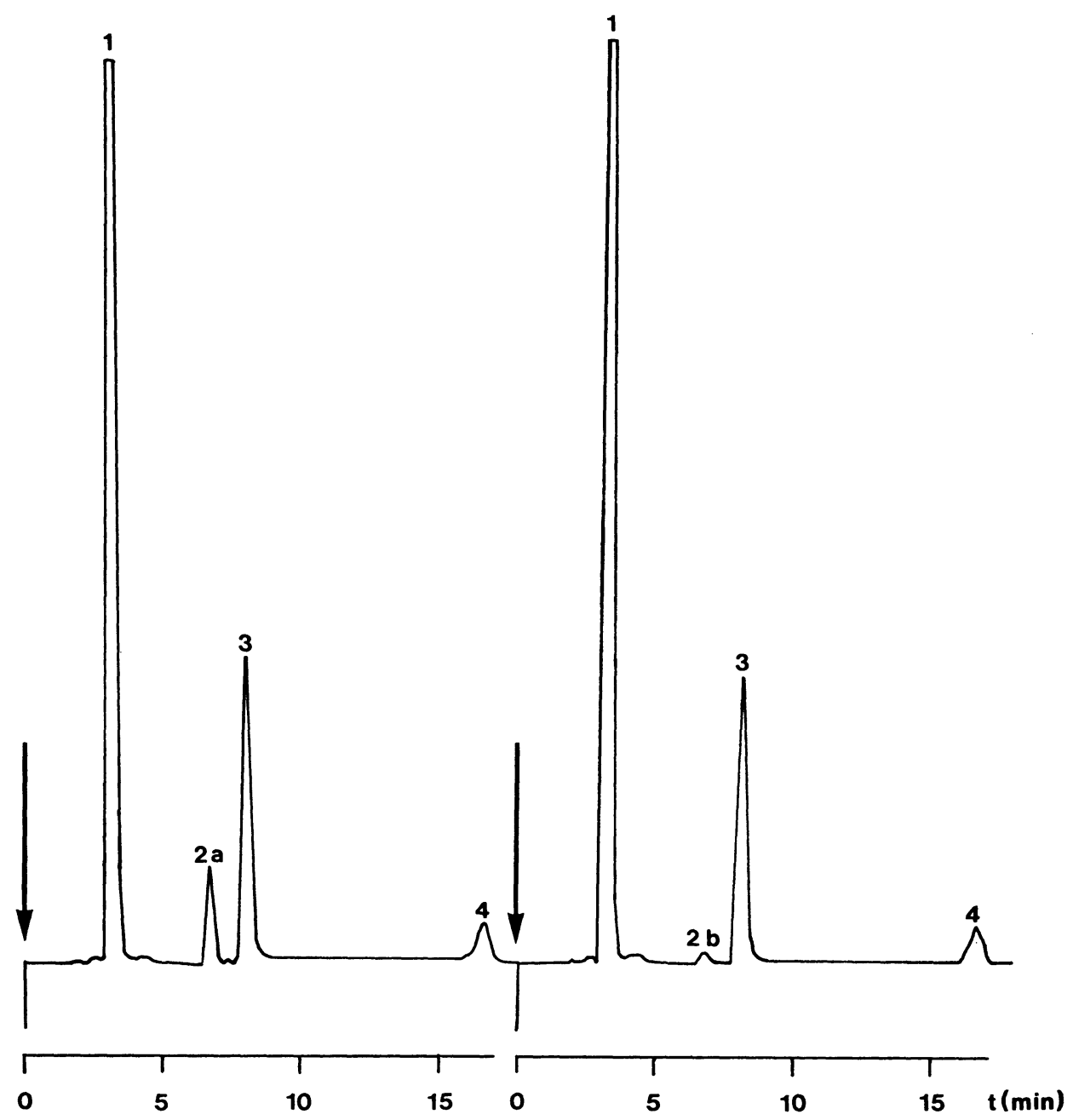

F ig u re 1. Liquid-chromatogram of the ether extract of a sample before adding a preservative and after 14 days. Peak identifications: $1=$ solvent. 2 = zearalenone: a before addition of a preservative, b the same sample 14 days after addition of a preservative ("Gasol"). 3 = diethylstilbestrol. 4 = impurity of diethylstilbestrol.

moinen 1979) modified using diethylstilbestrol as an internal standard. In Fig. 1 a chromatogram is shown of 2 grain samples before adding a preservative and 14 days after addition of "Gasol".

Bioassay method. Because part of the zearalenone remained in the solid residue of the inoculated grain after 
extraction when the liquid-chromatographic method was used (Kallela \& Saastamoinen 1979), an attempt was made to estimate this part of the toxin in another way. Immature female rats were fed with feed containing known quantities of zearalenone. Comparing the estrogenic effects of those with the results which were gained when rats were fed on the solid residues of the extracted grain samples it was possible to estimate semiquantitatively the amount of zearalenone which remained insoluble in the grain after extraction.

Bioassay methods used:

1. Determination of the estrogenic effect of known doses of zearalenone.

Three weeks old female rats were used for the bioassay. The estrogenic effects of zearalenone was estimated according to changes in uterine weights, uterine liquid contents and vaginal openings as described previously (Kallela et al. 1978). The following amounts of zearalenone: 25 - 50 - 75 - 100 $150-200-250-300-350-400-500-600$ and $800 \mu \mathrm{g}$ per rat were mixed to the feed of rats over a period of 5 days. The rats were fed once a day.

2. Determination of the estrogenic effect of the solid residues of extracted samples.

For the determination of the estrogenic effect of the solid residues of the extracted samples the bioassay method previously described was used (Kallela et al. 1978). Semiquantitative calculations were carried out by using uterine weight as criteria. A solid residue of $0.25 \mathrm{~g}$ dry matter per rat per day was mixed with the maintenance feed and administered daily.

\section{RESULTS}

\section{Growth of Fusarium graminearum}

No visible mycelium was developed during any period of storage on the Petri dish cultures which were treated with the preservatives "Gasol" or "Luprosil@". However on the untreated grain substrates mycelium was detectable after 1 or 2 days of storage and abundant after 3 days. After 2 weeks the mycelium began to wither, and after 4 weeks it changed to a thin brownish membrane. 


\section{Determination of zearalenone}

Li quid chrom at og raphy. The results of the liquidchromatographic investigations indicating the zearalenone contents of mold cultures grown on oats substrates are collected in Table 1.

T a ble 1. Amounts of zearalenone of oats cultures (liquid-chromatographic determination).

\begin{tabular}{|c|c|c|c|c|}
\hline \multirow{3}{*}{$\begin{array}{l}\text { Feed sample: } \\
\text { milled oats }\end{array}$} & \multicolumn{4}{|c|}{ Zearalenone ppm of dry weight of substrate } \\
\hline & & stora & eriod & \\
\hline & 0 day & 3 days & 14 days & 28 days \\
\hline no preservative & 1594 & 1660 & 2190 & 1973 \\
\hline + “Luprosil@” & $1594^{*}$ & 1409 & 1407 & 1365 \\
\hline + "Gasol" & $1594^{\star}$ & 544 & 225 & 108 \\
\hline
\end{tabular}

* determinations before adding preservatives.

All data in Table 1 are averages of 2 parallel determinations. At least 3 liquid-chromatographic evaluations were performed for each of them.

The toxin content of the grain substrate treated with "Gasol" was distinctly lower than in other samples after 3 days of storage. When the storage period continued the toxin content of these samples decreased further. Statistically the loss of toxin is highly significant in all of these cases. The quantity of toxin of the feed grain treated with "Luprosilß" declined slightly too, and after 14 and 28 days of storage the decrease was nearly significant. However in the untreated feed grain the toxin quantity increased. After 14 days of storage it was almost statistically significantly higher than at the commencement of storage.

B i o a s a y. The effect of known doses of zearalenone on the uterine weight, uterine liquid content and vaginal opening of immature female rats is shown in Table 2. The effect of increasing amounts of zearalenone ( $\mu \mathrm{g} / \mathrm{day}$ ) on the uterine weight is also shown in Fig. 2.

The estrogenic effect of the solid residues of the extracted samples on uterine weight, uterine liquid content and vaginal opening of immature female rats is shown in Table 3 . In addition, the zearalenone amounts are estimated semiquantitatively on the basis of bioassay results (uterine weights) which have been calculated using the contributory values of Fig. 2. 
T a b l e 2. Effect of known zearalenone quantities on uterine weight, uterine liquid content and vaginal opening of immature female rats.

\begin{tabular}{|c|c|c|c|c|}
\hline \multicolumn{2}{|c|}{ Treatment } & \multicolumn{3}{|c|}{ Effect on } \\
\hline $\begin{array}{l}\text { Zearalenone } \\
\mu \mathrm{g} / \text { day per rat } \\
\text { for } 5 \text { days }\end{array}$ & $\begin{array}{c}\text { Group size } \\
\text { (number of } \\
\text { rats) }\end{array}$ & $\begin{array}{c}\text { uterine } \\
\text { weight } \\
\text { mg }\end{array}$ & $\begin{array}{l}\text { uterine } \\
\text { liquid } \\
\text { content }\end{array}$ & $\begin{array}{c}\text { vaginal } \\
\text { opening } \\
\%\end{array}$ \\
\hline - & 8 & 18.7 & - & 0 \\
\hline 25 & 10 & 30.0 & - & 0 \\
\hline 50 & 15 & 50.5 & - & 0 \\
\hline 75 & 10 & 74.0 & $(+)$ & 0 \\
\hline 100 & 15 & 82.0 & + & 6.7 \\
\hline 150 & 15 & 98.3 & + & 6.7 \\
\hline 200 & 19 & 108.5 & $+(+)$ & 36.8 \\
\hline 250 & 15 & 119.5 & ++ & 73.3 \\
\hline 300 & 15 & 114.1 & ++ & 46.7 \\
\hline 350 & 5 & 117.8 & ++ & 80.0 \\
\hline 400 & 10 & 128.9 & ++ & 80.0 \\
\hline 500 & 5 & 101.5 & + & 100.0 \\
\hline 600 & 5 & 121.7 & ++ & 100.0 \\
\hline 800 & 5 & 122.5 & ++ & 100.0 \\
\hline
\end{tabular}

$$
\begin{aligned}
& +\quad=\text { slight } \\
& ++=\text { moderate } \\
& +++=\text { abundant }
\end{aligned}
$$

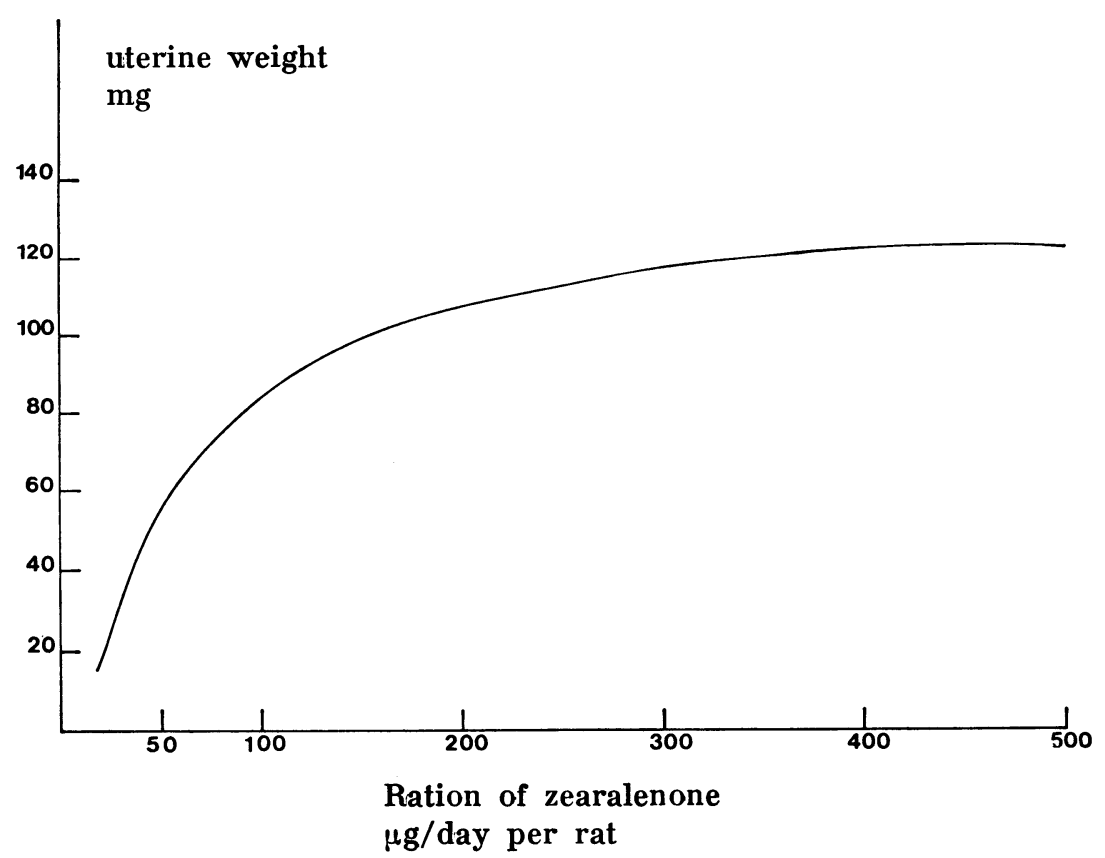

Figure 2. Effect of zearalenone on uterine weight of immature female rats. 
T a b le 3. Estrogenic effect and zearalenone content of the solid residues of extracted oats cultures.

\begin{tabular}{|c|c|c|c|c|c|c|}
\hline \multirow{2}{*}{$\begin{array}{l}\text { Residue } \\
0.25 \mathrm{~g} / \text { day } \\
\text { per rat } \\
\text { for } 5 \text { days }\end{array}$} & \multirow{2}{*}{$\begin{array}{c}\text { Group } \\
\text { size } \\
\text { (number } \\
\text { of rats) }\end{array}$} & \multirow{2}{*}{$\begin{array}{l}\text { Storage } \\
\text { time, } \\
\text { days }\end{array}$} & \multicolumn{3}{|c|}{ Effect on } & \multirow{2}{*}{$\begin{array}{l}\text { Zearalenone } \\
\text { content } \\
\text { ppm of dry } \\
\text { matter }\end{array}$} \\
\hline & & & $\begin{array}{c}\text { uterine } \\
\text { weight, } \\
\text { mg }\end{array}$ & $\begin{array}{l}\text { uterine } \\
\text { liquid } \\
\text { content }\end{array}$ & $\begin{array}{l}\text { Vaginal } \\
\text { opening } \\
\text { (number } \\
\text { of rats) }\end{array}$ & \\
\hline \multirow[t]{4}{*}{ no preservative } & 5 & 0 & 111.9 & ++ & 1 & 930 \\
\hline & , & 3 & 109.5 & ++ & 3 & 870 \\
\hline & $"$ & 14 & 112.6 & ++ & 2 & 957 \\
\hline & 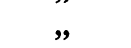 & 28 & 113.3 & ++ & 2 & 978 \\
\hline \multirow[t]{4}{*}{ “Luprosil@” } & ” & $0^{1}$ & 111.9 & ++ & 1 & 930 \\
\hline & , & 3 & 103.8 & + & 2 & 662 \\
\hline & 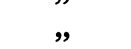 & 14 & 113.5 & +++ & 4 & 996 \\
\hline & ” & 28 & 121.9 & ++ & 3 & 1450 \\
\hline \multirow[t]{4}{*}{ “Gasol” } & , & $0^{1}$ & 111.9 & $+t$ & 1 & 930 \\
\hline & " & 3 & 81.4 & $(+)$ & - & 374 \\
\hline & , & 14 & 50.9 & - & - & 178 \\
\hline & , & 28 & 37.4 & 一 & - & 135 \\
\hline
\end{tabular}

1 determination before adding preservative

$+\quad=$ slight

$++=$ moderate

$+++=$ abundant

The estrogenic effect of the solid residues of the extracted samples obviously decreases when storage time is extended and when the preservation is performed with "Gasol". The loss in uterine weights after 3 days of storage is statistically highly significant. No changes occur in uterine weights which were obvious and statistically detectable when the rats were fed with untreated and with "Luprosil@" preserved feed grain.

The total amount of zearalenone in feed grain

Quantitative (liquid-chromatographic) and semiquantitative (determined by bioassay) zearalenone contents of oats samples treated in different ways and stored over different periods of time are shown in Table 4.

It can be seen in Table 4 that in infected grain samples in which the preservative "Luprosil@" is used the total toxin amount remains practically constant during the whole time of the experiment, but decreases abruptly when "Gasol" is used. If no preservative is used, the toxin content of grain increases gently when the storage period is continued. 
T a b l e 4. Total amount of zearalenone of feed grain samples.

\begin{tabular}{|c|c|c|c|c|}
\hline \multirow[t]{2}{*}{$\begin{array}{l}\text { Sample: } \\
\text { milled oats }\end{array}$} & \multirow{2}{*}{$\begin{array}{l}\text { Storage } \\
\text { period, } \\
\text { days }\end{array}$} & \multicolumn{3}{|c|}{$\begin{array}{c}\text { Zearalenone } \\
\text { ppm of dry weight of substrate }\end{array}$} \\
\hline & & $\begin{array}{c}\text { liquid- } \\
\text { chromatographic } \\
\text { determination }\end{array}$ & $\begin{array}{l}\text { bioassay } \\
\text { estimation }\end{array}$ & total \\
\hline \multirow[t]{4}{*}{ no preservative } & $\mathbf{0}$ & 1594 & 930 & 2524 \\
\hline & 3 & 1660 & 870 & 2530 \\
\hline & 14 & 2190 & 957 & 3147 \\
\hline & 28 & 1973 & 978 & 2951 \\
\hline \multirow[t]{4}{*}{ “Luprosil@”" } & $0^{*}$ & 1594 & 930 & 2524 \\
\hline & $\mathbf{3}$ & 1409 & 662 & 2071 \\
\hline & 14 & 1407 & 996 & 2403 \\
\hline & 28 & 1365 & 1450 & 2815 \\
\hline \multirow[t]{4}{*}{ "Gasol" } & $0^{*}$ & 1594 & 930 & 2524 \\
\hline & 3 & 554 & 374 & 928 \\
\hline & 14 & 225 & 178 & 403 \\
\hline & 28 & 108 & 135 & 243 \\
\hline
\end{tabular}

* determinations before adding preservative

\section{DISCUSSION}

The 2 preservatives, "Luprosilß" (propionic acid) and "Gasol" completely prevented visible growth of the fungus Fusarium graminearum. The complete opposite was noticed in the case of untreated oats where the mycelium was seen to be growing vigorously at commencement of storage, but withered when the storage period was extended and growth conditions became worse.

The toxin quantity formed in grain was affected in different ways by propionic acid and "Gasol". "Gasol" decreased the amount of toxin and the estrogenic effect by decreasing the amount of the toxin. However, "Luprosil@" (propionic acid) had no corresponding effect.

The decrease of the mycotoxin content of grain (oats) treated with "Gasol" was proved both in the ether extracts of oats cultures by liquid chromatography and in the solid residues of these extracted grain cultures semiquantitatively by the bioassay method. The liquid chromatographic determination proved that the toxin content decreased in 3 days of storage approximately $65 \%(1594 \rightarrow 554 \mathrm{mg} / \mathrm{kg}$ dry matter), in 14 days about $86 \%$ $(1594 \rightarrow 885)$ and in 28 days roughly $93 \%(1594 \rightarrow 108)$ (Table 1 and 4 ). The semiquantitative determination of the solid residues of the extracted grain cultures showed correspondingly that 
the amount of zearalenone decreased in 3 days approximately by $60 \%$, in 14 days by about $80 \%$ and in 28 days roughly by $85 \%$ (Table 3 and 4 ).

No corresponding loss of toxin occurred in grain preserved with "Luprosilß" (propionic acid). The liquid chromatographic investigation showed, in this case also, some loss of toxin in the ether extract, but it might be due to the fact that in this case the amount of toxin which remained in the solid residue was correspondingly higher, as shown by bioassay (Table 3 and 4 ).

As a function of time the percentage of zearalenone per unit of dry matter increased in the untreated stored grain samples (Table 4). However, it can not be said that the absolute amount of zearalenone became higher, because the increase of the percentage of the toxin may have been due to the loss of dry matter of grain mass caused by biological decomposition reactions which occurred in it.

Concerning the bioassay results, attention was paid to all criteria of uterine weight, uterine liquid content and vaginal opening. Of all these aspects the determination of uterine weight was considered to be most important. All calculations were determined by using uterine weight as a criterium. The results indicating the uterine liquid content and the vaginal opening were usually concordant and support the reliability of the estrogenic effect estimated according to the uterine weight.

The circumstances which eventually had influenced the decrease of the toxin quantities by "Gasol" preservation are still unexplained. The reaction is, however, obviously not barely chemical. No decrease in the zearalenone quantity occurred in a test tube which contained pure zearalenone dissolved in ethyl acetate or alcohol and "Gasol" (unpublished information).

In the present study, the admission of air into the Petri dishes was stopped by wrapping them hermetically in sheets of parafilm. In this manner attempts were made under laboratory conditions (considering the supply of oxygen) to simulate circumstances which prevail in the internal parts of grain mass from which oxygen is quickly consumed by biological reactions. Research is presently being carried out to solve the question in which manner preservatives have an effect on the growth and amount of zearalenone of Fusarium graminearum under conditions which resemble circumstances found on the surface layers of stored grain masses especially as far as oxygen supply is concerned. 


\section{REFERENCES}

Christensen, C. M.: Zearalenone. In Shimola, W. (ed) Conference on mycotoxins in animal feeds and grains related to animal health. Bureau of Vet. Med. Food, Maryland 1979, pp. 1-79.

Kallela, K. \& I. Saastamoinen: A simple method of determining zearalenone in cereals by liquid chromatography. Europ. J. appl. Microbiol. Biotechnol. 1979, 8, 135-138.

Kallela, K., E-L. Hintikka \& A. Ylimäki: Variation of F-2 toxin production on different substrates. Nord. Vet.-Med. 1978, 30, 424429.

Lasztity, R., K. Tamas \& L. Woller: Occurrence of Fusarium mycotoxins in some Hungarian corn crops and the possibilities of detoxification. Ann. Nutr. Alim. 1977, 31, 495-497.

Roine, K., E-L. Korpinen \& K. Kallela: Mycotoxicosis as a probable cause of infertility in dairy cows. Nord. Vet.-Med. 1971, 23, $628-633$.

Uoti, J. \& A. Ylimäki: The occurrence of Fusarium species in cereal grain in Finland. Ann. agric. fenn. 1974, 13, 5-17.

\section{SAMMANFATTNING}

Effekten av konserveringsmedel på växt av Fusarium graminearum och på mängden zearalenone.

Två konserveringsmedel för spannmål, „Luprosilß“ (verksam betåndsdel propionsyra) och „Gasol“ (organiska syror jämte tilläggsmedel) undersöktes beträffande effekten på mycelieväxten och toxinhalten i spannmål (havre) kontaminerat med Fusarium graminearum och innehållande toxinet zearalenon.

Innan konserveringsmedlen tillsattes bestämdes toxinhalten i havrekulturerna genom vätskekromatografi på eterextrakt. Eventuellt kvarbliven östrogen effekt $i$ mediet bestämdes semikvantitativt med biologisk test på juvenila honråttor. Den totala mängden toxin i det kontaminerade spannmålet visade sig vara $2,5 \mathrm{mg} / \mathrm{g}$ torrsubstans. Torrsubstanshalten var $37 \%$.

Den använda mängden konserveringsmedel per gram torrsubstans var 0,08 ml för „Luprosil@“ och 0,12 ml för „Gasol“, matsvarande 1-11/2 gånger den rekommenderade koncentrationen för respektive medel.

Båda konserveringsmedlen förhindrade fullständigt växten av mycelium. Toxininnehållet $i$ havren påverkades inte av propionsyra (,Luprosilß“), däremot förorsakade „Gasol“ inom 3 dagar en minskning på $60 \%$ i den initiala toxinhalten. Efter 2 veckor var minskningen $85 \%$ och efter 4 veckor $90 \%$.

Undersökningar beträffande verkningssättet fortgår.

(Received July 3, 1981).

Reprints may be requested from: K. Kallela, the Department of Animal Hygiene, College of Veterinary Medicine, Hämeentie 57, SF-00550 Helsinki 55, Finland. 